\title{
Imparting Surgical Training in Private Practice
}

\author{
K. Lakshman
}

Received: 11 March 2013 / Published online: 22 March 2013

(C) Association of Surgeons of India 2013

Keywords Private surgery · Private practice . Surgical education $\cdot$ Surgical training

The conventional view of private practice sees a private surgeon plying his trade either on a 'fee for service' basis or employed for a 'substantial' retainer in a private hospital. He provides 'exclusive' service to a select few. He is readily available to his patients round the clock, many times attending to their calls on the mobile phone, anytime of the day or night, with no restrictions to access. Outpatient visits are tailored to suit the patient. Many times, the timing of elective surgery is determined by the patient. This may even be at very 'odd' hours determined by the local 'soothsayer' based on the horoscope of the patient! If this view is indeed true, how could one even think of training juniors in a set-up like this? Is it not a breach of trust? Is the 'paying' patient not entitled to an exclusive and personal attention from the private surgeon in all aspects of his surgical care?

If one takes a reality check, it is clear that these questions become redundant in modern day surgical practice. The 'conventional' view is a narrow one. Surgical care has gone well beyond these considerations. Surgical care today is a complex and technology-oriented process that needs inputs from a team of people with varied skill sets. The round-the-clock 'cover' given by 'juniors' is a very important component of this process.

The role of a surgical specialist has been very well defined by the CANMEDS document [1]. The role is no more restricted to delivering surgical care only. The scope is much wider. The surgeon is at once a communicator, a collaborator, a scholar, a professional, a health advocate and a manager! This role is independent of whether the surgeon is in private practice or works for a teaching/government institution.

K. Lakshman $(\bowtie)$

58/4, 2nd Main, 1st Block, Thyagarajanagar, Bangalore 560028, India e-mail: Klakshman58@gmail.com
The World Medical Association, in its position statement on ethics governing medical care, makes it clear that it is the ethical responsibility of every doctor to share his knowledge with other medical professionals. The quote in chapter 4 of the Manual on Ethics brought out by the World Medical Association [2] states the following:

The Declaration of Geneva puts it this way: "I will give to my teachers the respect and gratitude that is their due." Although present-day medical education involves multiple student-teacher interactions rather than the oneon-one relationship of former times, it is still dependent on the good will and dedication of practising physicians, who often receive no remuneration for their teaching activities. Medical students and other medical trainees owe a debt of gratitude to their teachers, without whom medical education would be reduced to self-instruction.

Another important aspect of health care that necessitates the involvement of private work in teaching is the fact that 75 $80 \%$ of health care in our country is delivered in the private sector [3]. About $80 \%$ of doctors work in the private sector, and $85 \%$ of outpatient visits and $60 \%$ of inpatient care occur in the private sector [4]. It would be unreasonable to expect to meet all the training requirement of the country, from only $20 \%$ of the patient population that visits government institutions for health care. The large patient load in the private sector has to be harnessed for training purposes. This has to happen without breaking ethical principles and the trust that patients have in us.

In this context, we have a lot to learn from the American residency programmes. William Halstead is credited with devising the core of the residency programme as we know it today. The model of training was basically one of apprenticeship. Trainees worked with the chiefs, being actively involved in patient care. They were given increasing clinical and operating responsibilities as the training progressed. Indigenous poor patients in general wards were involved in the training process. Paying patients were attended to exclusively by the chiefs [5]. The infirmaries in UK in the 
eighteenth century also had similar arrangements [6].Over a period of time, the thought evolved that 'using' only general ward patients for training would be ethically unacceptable. Eventually, training encompassed all patients, and surgical care became a true 'teamwork'. This was a win-win situation for all stakeholders - the patients, the trainers and the trainees as nicely articulated by Dr. Francis Moore [7].

...all patients who enter the door of the hospital, the emergency ward, or the outpatient department acknowledge that their care will be managed by a team that basically consists of two individuals, a teacher and a learner... The care and responsibility are shared by both members of the team.... In the single-standard system, the teacher-learner relation is assumed.

\section{Dr. Moore goes on to say,}

...always a little shocking to visit a teaching hospital in which the older man, the teacher, does the operation from start to finish in an entirely non-sharing mode, only to leave the hospital and go somewhere else or home to bed for the night, leaving $100 \%$ responsibility for all other aspects of the patient's care to the learner,... obviously an unhealthy and unethical situation

What does society and the patient populations think of training in private health care? Again, we can learn from the experience of Americans. In the 1970s, a popular TV programme, ' 60 min', accused American surgeons of being 'ghost surgeons' [7]. It went on to claim that trainees do most of the work and the chiefs are not really operating as they claim. The surgical establishment made a concerted effort and successfully changed this perception. It explained the need for teamwork in surgery. It went on to delineate the collective responsibility of surgeons and patients to see to it that a new generation of competent surgeons is trained for the future. And, finally, it explained that this training process does not put the patients at any increased risk as the trainees are closely supervised. This latter aspect has been clearly proven in many studies [8].

But can the experience of American society be extrapolated to the Indian ethos and culture? We did a survey of our patients in a private corporate hospital (paper being processed for publication). We explained to them that we are trying to learn about their attitudes towards training of juniors, having first clarified that the chief surgeon monitors the work of the juniors closely. A good 75-80\% of patients surveyed had no hesitation in parts of the health care being delivered by trainees; this included parts of the operation being done by trainees, as long as the chief was personally present at surgery. While not many such studies are available in the literature, the few that are available both support and refute this view [9]. Significantly, the higher the educational level of the patient, the greater are the chances of the patient refusing to allow resident involvement in surgery [10].

Finally, it is important to recognize the positive aspects of training on the private surgeon. Teaching makes one question oneself; one keeps in touch with the latest trends in surgical care. Practice becomes evidence based. One gets the discipline of collecting data. Documentation improves. Audits and analyses of data will lead to improvement in one's practice. Publications and presentations add to one's defence if one's practice is medico-legally challenged. In fact, an institution with a strong surgical education programme will have a better morbidity and mortality record than non-training institutions [11].

To conclude, teaching and sharing knowledge must be a part of every surgeon's life. Being in private practice does not absolve the surgeon of his social responsibility to train the next generation of surgeons. Such training falls well within the ethical framework of private surgical care. A proactive involvement in teaching and training from private surgeons is a win-win situation for all stakeholders in surgical care.

\section{References}

1. Royal College of Physicians and Surgeons of Canada (2005) The CANMEDS framework. http://www.royalcollege.ca/portal/page/ portal/rc/canmeds/framework. Accessed 8 Mar 2013

2. World Medical Association (2009) Medical ethics manual. http:// www.wma.net/en/30publications/30ethicsmanual/pdf/ethics manual_en.pdfpp 85. Accessed 8 Mar 2013.

3. Shetty KR (2006) Medical practice-medical education-medical insurance. Bombay Hospital Journal. http://www.bhj.org/journal/ 2006_4801_jan/html/sp_fe_medical_79-84.html. Accessed $17 \mathrm{Jul}$ 2007.

4. National Commission on Macroeconomics and Health (2005) Private sector in healthcare delivery in India-report of National Commission on Macroeconomics and Health. http://www.nihfw.org/WBI/docs/PPP_SessionBriefs/PPP\% 20 Course $\% 20$ sessions/Need $\% 20$ and $\% 20$ Scope $\% 20$ for $\% 20 \mathrm{PPP} /$ Private $\% 20$ Sector $\% 20$ in $\% 20$ Health $\% 20$ Care $\% 20$ Delivery $\% 20$ in $\%$ 20India.pdf. Accessed 8 Mar 2013.

5. Pellegrini CA (2006) Surgical education in the United States. Annals of Surg 244:335-342

6. Jones JW, McCullough LB, Richman BW (2003) Do unto others: justice in surgical education. Surgery 133:443-444

7. Greif JM (1980) A study of the role of private patients in surgical training programs: a resident's viewpoint. Bull NY Acad Med 56:385-392

8. Thorpe P (2004) Training and patient safety. Brit J Surg 91:391-392

9. Nguyen TN, Silver D, Arthurs B (2005) Consent to cataract surgery performed by residents. Can J Ophthal 40:34-37

10. Goh LW, Lim AYT (2007) Surgical training in Singapore: will patients consent to trainee surgeons performing their operations? Ann Acad Med Singap 36:995-1002

11. Shooner C (1997) The ethics of learning from patients. Can Med Assoc J 156:535-538 